\title{
HANDBOOK OF HEALTH
}





\section{HANDBOOK OF HEALTH FOR OVERSEAS SERVICE}

BY

George Cheever Shattuck, M.D.

AND

William Jason Mixter, M.D.

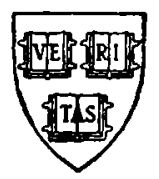

SECOND EDITION, REVISED

HARVARD UNIVERSITY PRESS

CAMBRIDGE, MASSACHUSETTS

1944 
COPYRIGHT 1942, 1943

BY GEORGE CHEEVER BHATTUCK

Third Printing

PRINTED AT THE HARVARD UNIVERSITY PRINTING OFFICE CAMBRIDGE, MASS., U.S.A. 